Available online on 15.03.2021 at http://ujpr.org
Universal Journal of Pharmaceutical Research
An International Peer Reviewed Journal
Open access to Pharmaceutical research is an open access article distributed under the terms of the Creative Commons Attribution-Non
Commercial Share Alike 4.0 License which permits unrestricted non commercial use,
provided the original work is properly cited
Volume 6, Issue 1, 2021

\title{
LOCAL EXPERIENCE OF TELEMEDICINE: EXAMPLES OF CASES IN YEMEN
}

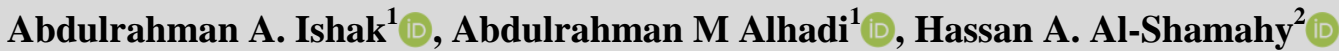

${ }^{I}$ Department of Pediatrics, Faculty of Medicine and Health Sciences, Sana' a University, Sana 'a, Republic of Yemen. ${ }^{2}$ Medical Microbiology and Clinical Immunology Department, Faculty of Medicine and Health Sciences, Sana'a University, Republic of Yemen.

\section{ABSTRACT}

Background: The benefits of establishing a web-based telemedicine service in a resource-stressed society, linking health professionals in order to improve the quality and accessibility of healthcare and facilitate a further method of medical education through exchange of knowledge and experiences. Sub-standard communication facilities within a strained medical service across limited sites, combined with an inadequate understanding of the service further reduces provision. The on-going military campaign within the country exacerbates the problems facing medical staff, yet despite the difficult situation in the country there is a drive towards an increase in health facilities.

Objective: The aim of this research is to explore one of the first experiences in the use of telemedicine in Yemen by clarifying cases that have benefited from telemedicine and further exploring the potential for development of a network of TM to serve areas which lack sub-specialty services.

Methods: We carried out a review of both the first and second phases of our experience of TM services in Yemen. The first phase began in 1997 when we joined a newly established international company based in the USA with several offices in different countries. We got a huge, expensive digitizer that was supposed to transfer medical reports to second opinion sites in USA, UK, Jordan etc. The second phase began a few years later utilizing a free service, namely The Swinfen Charitable Trust, based in the $\mathrm{UK}$; in which 300 cases in the first stage with 1-3 responses and about 80 cases with 5-50 responses and more in the second stage were involved and benefited from TM services.

Results: During the study period the process was seen to be generally very useful to patients helping the local doctor to give the correct decision on management and treatment; added to that cases had reduced travel and the specialist advice proved educational for the doctors who received their guidance.

Conclusion and recommendation: This study revealed that telemedicine services are generally underutilized in Yemen despite the good results achieved in many of the cases. Technical, administrative, and legal issues should be discussed in Yemen. Factors such as on-going problems with internet connectivity and consequent system reliability must also be considered. Knowing and identifying these factors is vital for considering any future in-depth studies and assessing the appropriate measures to fix the technological problems that face TM in Yemen are an on-going concern.

Keywords: Local experience, Telemedicine TM, Yemen.

Y

Article Info: Received 3 January 2021; Revised 8 February; Accepted 5 March, Available online 15 March 2021

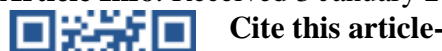

Ishak AA, Alhadi AM, Al-Shamahy HA. Local experience of telemedicine: examples of cases in Yemen. Universal Journal of Pharmaceutical Research 2021; 6(1):34-37.

DOI: https://doi.org/10.22270/ujpr.v6i1.537

口. Address for Correspondence:
Prof. Hassan A. Al-Shamahy, Faculty of Medicin

Prof. Hassan A. Al-Shamahy, Faculty of Medicine and Heath Sciences, Sana'a University, P.O. Box 775 Sana'a, Yemen. Tel+967-770299847; E-mail: shmahe@yemen.net.ye

\section{INTRODUCTION}

One of the greatest challenges that face humankind in the $21^{\text {st }}$ century is the ability to make high-quality health care provision for all. Although the vision of WHO is health for all, in reality this is difficult, perhaps impossible, because of the loads imposed on an increasing world population by chronic and acute diseases, rising opportunities for health, and socioeconomic conditions of the society that increase inequalities in health status between and within countries. Traditionally the provider of the medical expertise and the patient were present in the same place at the same time. The advancement of information and communication technologies has created chances for overcoming this problem by generating alternative ways of accessing health care by using telemedicine services $^{1-4}$. 
Telemedicine is the use of information communication technology to deliver health care services from one location to another in different approaches (for example store and forward, real-time and remote monitoring) and has the capability to increase the quality and access to health care provision, to lower patient costs and to educate local health care providers at the same time. Telemedicine is an alternative way of supporting local health care services in low-resource settings and developing countries like Yemen. Telemedicine includes confident transmission of medical data and information, for instance, images, biological/physiological measurements, audio, video, or any other type of data needed for prevention, diagnosis and treatment, follow-up and monitoring of patients $^{4-7}$. Telemedicine services range from treating individual patients to supporting a healthcare system as a whole; from single mobile consultations up to advice on the most complex surgical procedures and thus plays an important role in providing solutions for many health challenges beyond the normal experience of the local provider. For instance, telemedicine can allow access and link specialists to a specific patient, allowing the ability to diagnose from a distance, and to then monitor and recommend further treatment for those patients located in remote areas. A functioning, capable telemedicine service is proving to be one of the most promising forms of assistance in health care in developing countries by using information and communication technologies to direct a number of of the societal health challenges faced inside those local areas $^{6-8}$.

TM has been introduced to many countries in Asia, Africa and Latin America. Progress differs from country to country. The general impression is that all countries are expanding the service in spite of the problems related to the gap between international development strategies and local realities ${ }^{4}$. We have completed a comprehensive evaluation of the services we have received with our telemedical partners. The aim of this research is to explore one of the first experiences in the use of telemedicine in Yemen by clarifying cases that have benefited from telemedicine and exploring the potential for development of a network of TM to serve areas which lack sub-specialty services.

\section{METHODS}

The first stage of our experience of TM services in Yemen goes back to 1997. At that time, we joined a newly established international company based in the USA with several offices in different countries. We got a huge, expensive digitizer that was supposed to transfer medical reports to the second opinion sites in USA, UK and Jordan. Around 300 cases were carried out over a period of approximately 4 years. It was essential to cover via email and post in order to transfer cases due to the failure of the digitizer. The second stage continued a few years later utilizing the excellent and highly qualified free service. The Swinfen Charitable Trust based in the UK. With this service approximately 200 cases benefited from consultation and the majority of these were cases that continued with follow up advice for a long period of time. The majority of cases in the first phase were sent to Jordan, a few cases to the UK and USA. The cases covered all specialties for adults and children: neurology, dermatology, ophthalmology, oncology, nephrology with a few cases requiring a laboratory second opinion. The second TM service surveyed was the excellent free service of the UK based charity, The Swinfen Charitable Trust, which has been used for 13 years. A secure web-based messaging system is used, which gives referring practitioners from more than 68 countries access to a panel of more than 514 consultants in the UK, USA, Australia, Canada, India and the Middle East, specializing in a wide range of disciplines. The service provides the local doctor with not only the initial second opinion but due to the excellent response system the follow-up consultations reach in some instances over 50 messages per individual case history. The number of consultations over the period of almost 13 years involved approximately 85 cases. The frequency of interaction with the consultants and the administrators who run the service varied - in some cases about 122 interactions over the years, other less complex cases were with minimum 5-10 interactions between primary physician in Yemen and the Trusts consultants.

\section{The benefits were:}

$>$ Educational to the primary opinion.

$>$ Provision of advice which was impossible to get locally due the constrains of cost and the great difficulty of travel which is impossible in almost all cases due to the financial cost and the current situation in Yemen.

$>$ Direct benefits to the patient included specialist drug prescription advice, surgical advice and specialized opinions in the field of further investigations (laboratory results, radiology images).

\section{RESULTS}

The service supplied to the patient, the educational benefits to the local practitioner, and the economic benefits from a Telemedical Service are illustrated below:

$>$ Of the few of cases where the image of the x-ray was sent to the USA is the case of the child who was a victim of a fall from a third floor building and suffered from several fractures at the elbow. A specialist in USA gave an excellent opinion to the local orthopedic surgeon, with surgical advice. The success of the operation was remarkable.

$>$ The artificial hip joint of a patient who had received the wrong postoperative physio at home was saved when given the proper advice in time.

$>$ Assessment of a patient with Brain cancer helped to determine that further medical treatment abroad would be without benefit, so his travel was stopped, relieving the burden on the patient and his family. 
$>$ A patient who suffered a gunshot wound to the spinal column. The whole spinal column had moved forward and the local surgeon received good and urgent advice for the necessary operation.

$>$ A consultation with a psychiatrist proved very educational and gave both benefit to the patient and a renewed trust in the local medical capability to handle the case. The discussion on possible drug use combined with the benefits of the local herb KATHA gave both sides the ability to exchange information which was very useful to the patient and furthered understanding of possible treatments.

> Management of some cases was followed by feedback from the treating physicians in Jordan and USA.

$>$ Direct benefit to the patient such as the case of a supraspinatus tear. Primary opinion thought that the patient needed a laparoscopic repair. The second opinion used the term I do not treat radiology. The advice of physiotherapy was very helpful achieving excellent results.

$>$ Cerebral palsy patient with recurrent convulsions and multiple deformities: in this case a neurologist, plastic surgeon and physiotherapist all responded to the primary request.

$>$ A child with adenoma in the parathyroid gland. Primary opinion of a general surgeon was to operate. The second opinion was very useful, excluding the surgical option and specifying the medication needed to treat the case.

$>$ A case of rheumatic heart disease: The artificial mitral valve was damaged because of failure to treat infection; sub-acute bacterial endocarditis caused neurological problems viz micro aneurysms developed, which was shown after the valve was replaced. The patient developed a coma and partial loss of vision. Follow up was done simultaneously between the primary doctor's treatment and a second opinion in London and via another system an opinion was taken from a center in Turkey as well.

$>$ The advice by a neurosurgeon in a case of severe trauma to the leg was very useful to the surgeon.

$>$ Child 11 years old with Acute myeloid leukemia who developed CNS infiltration. The result was the development of sever increase in intracranial pressure, sever papilledema, loss of control of urine and unsteady gait. The neurosurgeon prepared the child fro neuro surgical interference. Second opinion from Swifen was the surgery would be very dangerous and that medical treatment is expected to give good result. The condition recovered almost completely from the CNS problems. Urinary problems and the severe headache and gate improved markedly.

\section{DISCUSSION}

The current research has focused on patients and clinicians who have had experience with TM consultations in Yemen. The study is similar to most previous research that focused on patients or clinicians who have had experience with TM consultations in remote health areas ${ }^{\mathbf{8}, 9}$. The patients understood the benefit of receiving TM advice, and that this had the advantage of eliminating the burden associated with travel and the cost of seeking treatment outside Yemen. This finding is similar to that reported in rural settings in developed countries where the inconvenience and burden associated with travel and the cost of treatment outside their areas are eliminated by $\mathrm{TM}^{10,11}$.

Telemedicine services can be sighted as patientcentered, as a means of provided that the quality and level of care predictable from specialized services, in a location that is practical for the patient. One could argue that telemedicine services would be commonplace in a healthcare system that is truly patient-centered. Telemedicine is not only of value in developing countries such as Yemen but increasingly it has become a method prevalent in developed countries, as can be demonstrated in countries such as the UK during the Coronavirus Pandemic when people were prevented from moving easily to seek specialist advice $^{11}$. For patients to be able to ask for specialist services by TM, they need to know about TM and recognize the promises and also the limitations of receiving services throughout this modality. In addition, for patients to be able to receive TM services, their primary care provider needs to know how to access and refer to such a service ${ }^{11,12}$. Participants agreed the main benefits of TM are the reduced need for travel and they did not appear to be concerned about the limitations of TM or patient confidentiality concerns that have been reported in some of the literature $^{8-10}$.

Participants hinted at some of the barriers mentioned in the literature ${ }^{11,12}$, such as an unwillingness to change, but from our experience in this study, the lack of community awareness of the availability of telemedicine may be another important obstacle in Yemen. A national network capability together with national database facilities is the ideal end goal of TM in Yemen, as it is in many developed and developing countries. Such a facility is needed in all developing countries both for the sake of control and prevention of communicable disease and for the increased chance of wider educational purposes in local medical staff.

To come to the point: telemedicine can be advantageous to patients in remote communities and isolated regions, who can obtain care from doctors or specialists far away without the patient having to travel to visit them ${ }^{13}$. Current developments in mobile collaboration technology can permit healthcare professionals in multiple places to share information and discuss patient matters as if they were in the same place $^{14}$. Remote patient monitoring all through mobile technology can decrease the need for outpatient visits and allow distant prescription verification and drug administration oversight, potentially considerably reducing the overall cost of medical care ${ }^{15}$. It may also be preferable for patients with limited mobility, for example, patients with Parkinson's disease ${ }^{16}$.

Telemedicine can also facilitate medical education by allowing workers to observe experts in their fields and 
share best practices more easily ${ }^{17}$. Telemedicine also can eradicate the potential transmission of infectious diseases or parasites between patients and medical staff. This is mainly an issue where MRSA and other hospital acquired infections are concerns. Moreover, some patients who feel uncomfortable in a doctor's office may do better remotely. For example, white coat syndrome may be avoided. Patients who are homebound and would then require an ambulance to move them to a clinic are also a consideration ${ }^{14,17}$.

\section{CONCLUSION}

This paper attempts to search for solutions to improve the quality of health care services in Yemen through TM technology and to spread awareness among health workers and the community of the importance of this type of medicine. There are various reforms underway to improve Yemen's current healthcare indicators. The ICT infrastructure needs a strategic assessment in Yemen for the successful implementation of telemedicine services. $\mathrm{We}$ recommend the development of information and communication technology in Yemen to meet the needs of telemedicine. As well as establishing units in hospitals to carry out local TM care and to sponsor links with TM services abroad. This is a workable alternative to the lack of highly specialized services available in developing countries.

\section{CONFLICT OF INTEREST}

No conflict of interest associated with this work.

\section{AUTHOR'S CONTRIBUTION}

The first author presented the data and the first; second and the third authors analyzed the data and wrote, revised and edited the paper.

\section{ACKNOWLEDGEMENTS}

The authors express their thanks and appreciation to the Swinfen Charitable Trust, London, United Kingdom, which since 1999, the Swinfen Charitable Trust has been at the forefront of using the Internet to assist in the medical treatment of the poor, sick and disabled worldwide. Its humanitarian network is the longest not-for-profit remote medical network in existence. We thank Catherine Davis, the generous humanitarian who supports the telemedicine tradition in Yemen.

\section{REFERENCES}

1. Craig J, Victor Patterson. Introduction to the practice of telemedicine. J Telemed Telecare 2005;11(1): 3-9. https://doi.org/10.1177/1357633x0501100102

2. Ben-Pazi H, Browne P, Chan P, Cubo E, Guttman M, Hassan A, et al. The Promise of telemedicine for movement disorders: an interdisciplinary approach. Curr Neurol Neurosci Reports 2018; 18 (5): 26. https://doi.org/10.1007/s11910-018-0834-6

3. Smith AC, Gray LC. Telemedicine across the ages. Med J Aust 2009;190(1):15-9.

https://doi.org/10.5694/j.1326-5377.2009.tb02255.x

4. World Health Organization. Telemedicine: Opportunities and developments in Member States. Geneva: WHO 2009.

5. Van Gemert-Pijnen JE, Nijland $N$, van Limburg $M$, Ossebaard HC, Kelders SM, Eysenbach G, Seydel ER. A holistic framework to improve the uptake and impact of eHealth technologies. J Med Int Res 2011;13(4):e111. https://doi.org/10.2196/jmir.1672

6. Johansson AM, Söderberg S, Lindberg I. Views of residents of rural areas on accessibility to specialist care through video conference. Technol Health Care 2014; 22(1):147-155. https://doi.org/10.3233/thc-140776

7. Johnson DJ. Physician's emerging roles relating to trends in health information technology. Inform Health Soc Care 2014;114. https://doi.org/10.3109/17538157.2014.948172

8. Raven M, Butler C, Bywood P. Video-based telehealth in Australian primary health care: current use and future potential. Aust J Prim Health 2013; 19(4):283-286. https://doi.org/10.1071/PY13032

9. Moffatt JJ, Eley DS. Barriers to the up-take of telemedicine in Australia--a view from providers. Rural Remote Health 2011; 11(2):1581. PMID: 21385004

10. Sanders C, Rogers A, Bowen R, Bower P, Hirani S, Cartwright M, Fitzpatrick R, Knapp M, Barlow J, Hendy J. Exploring barriers to participation and adoption of telehealth and telecare within the Whole System Demonstrator trial: a qualitative study. BMC Health Serv Res 2012.;12(1):220. https://doi.org/10.1186/1472-6963-12-220

11. Cora Drew. Opportunities and challenges for telemedicine, Health capital 2011; 4(4):1-5

12. Rogove HJ, McArthur D, Demaerschalk BM, Vespa MP Telemedicine and e-health, Barriers to telemedicine: Survey of current users in acute care units 2012; 18(1):1-6. https://doi.org/10.1089/tmj.2011.0071

13. Berman M, Fenaughty A. Technology and managed care: patient benefits of telemedicine in a rural health care network. Health Economics Wiley 2005; 14 (6): 559-73. https://doi.org/10.1002/hec.952

14. Van't Haaff C. Virtually On-sight. Just for Canadian Doctors 2009; 22. Archived from the original (PDF) on 2012-03-24. https://en.wikipedia.org/wiki/Librestream

15. Saylor M. The Mobile Wave: How Mobile Intelligence Will Change Everything. Perseus Books/Vanguard Press 2012; 153.

16. Dorsey ER, Glidden AM, Holloway MR, Birbeck GL, Schwamm LH. Teleneurology and mobile technologies: the future of neurological care. Nature Reviews. Neurology 2018; 14 (5): 285-297. https://doi.org/10.1038/nrneurol.2018.31

17. Conde JG, De S, Hall RW, Johansen E, Meglan D, Peng GC. Telehealth innovations in health education and training. Telemed J E-Health 2010; 16 (1):103-106. https://doi.org/10.1089/tmj.2009.0152 